\title{
Capability Index-A Statistical Process Control Tool to Aid in Udder Health Control in Dairy Herds
}

\author{
J. Niza-Ribeiro, ${ }^{1}$ J. P. T. M. Noordhuizen, ${ }^{2}$ and J. C. Menezes ${ }^{3}$ \\ ${ }^{1}$ Segalab Laboratório de Sanidade Animal e Segurança Alimentar, \\ 4465-732 Leça do Bailio, Portugal \\ ${ }^{2}$ Department of Farm Animal Health, \\ Utrecht University, Utrecht, The Netherlands \\ ${ }^{3}$ Department of Chemical Engineering, IST \\ Technical University of Lisbon, 1049-001 Lisbon, Portugal
}

\section{ABSTRACT}

Bulk milk somatic cell count (BMSCC) averages have been used to evaluate udder health both at the individual or the herd level as well as milk quality and hygiene. The authors show that the BMSCC average is not the best tool to be used in udder health control programs and that it can be replaced with advantage by the capability index (Cpk). The Cpk is a statistical process control tool traditionally used by engineers to validate, monitor, and predict the expected behavior of processes or machines. The BMSCC data of 13 consecutive months of production from 414 dairy herds as well as SCC from all cows in the DHI program from 264 herds in the same period were collected. The Cpk and the annual BMSCC average (AAVG) of all the herds were calculated. Confronting the herd's performance explained by the Cpk and AAVG with the European Union (EU) official limit for BMSCC of 400,000 cells $/ \mathrm{mL}$, it was noticed that the Cpk accurately classified the compliance of the 414 farms, whereas the AAVG misclassified $166(40 \%)$ of the 414 selected farms. The annual prevalence of subclinical mastitis (SMP) of each herd was calculated with individual SCC data from the same 13 -mo period. Cows with more than 200,000 SCC/mL were considered as having subclinical mastitis. A logistic regression model to relate the Cpk and the herd's subclinical mastitis prevalence was calculated. The model is: $\mathrm{SMPe}=0.475 e^{(-0.5286 \times \mathrm{Cpk})}$. The validation of the model was carried out evaluating the relation between the observed SMP and the predicted SMPe, in terms of the linear correlation coefficient $\left(R^{2}\right)$ and the mean difference between SMP and SMPe (i.e., mean square error of prediction). The validation suggests that our model can be used to estimate the herd's SMP with the herd's Cpk. The Cpk equation relates the herd's

Received June 7, 2003.

Accepted January 16, 2004.

Corresponding author: J. Niza-Ribeiro; e-mail: niza.ribeiro@ agros.pt.
BMSCC with the EU official SCC limit, thus the logistic regression model enables the adoption of critical limits for subclinical mastitis, taking into consideration the legal standard for SCC.

(Key words: udder health control, capability index, statistical process control, dairy farm)

Abbreviation key: AAVG = annual average of BMSCC, AVG = monthly average of BMSCC, BMSCC = bulk milk somatic cell count, BMT = bulk milk tank, Cpk = capability index, EU = European Union, HACCP = hazard analysis and critical control point, $\mathbf{R}^{\prime}$ = annual average of the monthly range of the BMSCC, $\mathbf{R}_{\mathbf{i}}=$ monthly range of the BMSCC, $\mathbf{S M P}=$ annual subclinical mastitis prevalence, $\mathbf{S M P e}=$ estimated annual subclinical mastitis prevalence, $\mathbf{S P C}=$ statistical process control.

\section{INTRODUCTION}

Bulk milk somatic cell count (BMSCC) averages have been used for decades to evaluate both the udder health at the individual or at the herd level and milk quality and hygiene. The SCC in raw milk is directly related with the mammary gland level of infection with pathogens (Schalm et al., 1971; International Dairy Federation, 2000). Hence, SCC has been used in the last decades to assess the udder health status either at the cow (or quarter level) or the herd level (Radostits et al., 1994; Schukken et al., 1996). There are well-established relations between SCC and the herd prevalence of mastitis (Eberhart et al., 1982; Barkema et al. 1999), the milk composition (Klei et al., 1998; Koldeweij et al., 1999) and the production losses (Koldeweij et al., 1999). The costs relating SCC with losses at the farm level were extensively reviewed by Fetrow et al. (2000) and those relating SCC with fluid milk and cheese quality by Schällibaum (2001). The SCC in milk are therefore excellent indicators of the milk quality.

Because SCC is currently easy and cheap to test, farmers, the industry, and authorities use different 
types of more or less elaborated means such as arithmetic or geometric (International Dairy Federation, 1997) to monitor the herd health status and to define milk quality and udder health goals (Radostits et al., 1994; Schukken et al., 1996) as well as premiums or penalties for the milk that leaves the farm. Every mean, regardless of the way it is calculated, is a measure of central tendency. However, any population needs at least 2 parameters, the mean and the variance, to be properly described. As a consequence, the parameters used today to evaluate the BMSCC have a few drawbacks: the first is that the parameter does not adequately describe the herd's BMSCC distribution throughout the year, the second is that the BMSCC average is a poor indicator for compliance of the herd with the legal standard for SCC and, last, no predictive information about the expected future performance of the BMSCC can be derived from it.

To overcome these deficiencies, the herd was considered to be a production process unit, designed to produce milk from its various inputs (feed, genetics, infrastructures, and management) that goes through the "machine" (cow) into the bulk milk tank. The outputs of this process are the batches of milk leaving the herd, each batch being the bulk milk tank's content. It is necessary to consider the herd as a system of processes to facilitate a comparison between the herd production process and any type of industrial process and to apply total quality control methods at the herd level. Statistical process control (SPC) was developed by process control engineers to monitor, evaluate, and predict industrial process behavior (Wadsworth, 1998). Some authors have already made some incursions in this area (Reneau, 2000). The capability index (Cpk) is a main SPC tool currently used by engineers to evaluate the performance of processes or machines and to describe its current behavior as well as to predict the expected future performance (Mitra, 1993). The Cpk concept lumps together process performance statistics of the herd (a central tendency parameter and a dispersion one) with process performance specification criteriain this case the European Union (EU) legal standard for SCC in the bulk milk tank (BMT). Therefore, the Cpk makes a direct relation between the herd performance and the legal standard.

A process with a Cpk value equal to or greater than one is a good process because it consistently complies with the product's quality specifications. On the other hand, values of Cpk below one, especially the negative ones, represent inadequate processes (Ford, 1987; Mitra, 1993). We looked at the Cpk as a potential tool to connect herd udder health status and milk quality of the herd using the SCC of the bulk milk tank.
The purpose of this work was to evaluate the capability index, Cpk, as an instrument to measure dairy herd compliance with regulations as a replacement for the traditional herd BMSCC. The potential of Cpk to be used by veterinarians and farmers in udder health control programs, as well as its ability for vendor rating purposes in payment schemes, is also evaluated.

\section{MATERIALS AND METHODS}

\section{Data Used}

Two data sets, 1 and 2, were used in this work. Bulk milk SCC of 13 consecutive months from 414 dairy herds were part of the data set 1 . These data were taken from the regional quality control laboratory database. The laboratory receives approximately 3000 samples a day from about 6000 herds and, each day, randomly selects a number of these to perform at least 4 SCC tests a month per herd. Consequently, each herd had between 4 and 7 samples in the database. Every time a herd had more than 4 samples in a particular month, the 4 results were randomly selected among the available ones. For each herd a descriptive analysis was performed and SPC parameters were calculated (see next section).

Data set 2 was composed of the SCC of the individual lactating cows. These were taken from the DHIA database. Because only 264 of the previous 414 herds included in the data set 1 were registered in the DHIA, data set 2 contains cow data from only 264 herds. Eleven months per year the DHIA collects one milk sample from every cow in the herd and records, among other data, the cow's daily production and SCC results. From the database received from the DHIA, the number of the herd, the identity of the cow, the month of the record, and the corresponding SCC from a period corresponding to the same 13 mo recorded in data set 1 were selected. We then calculated cumulative annual subclinical mastitis prevalence (SMP), at the cow level, for each herd, as number of counts above $200,000 \mathrm{SCC} / \mathrm{mL}$ and the total number of cows tested in the herd in the period under evaluation (13 mo). The herd prevalence from data set 2 was combined with the Cpk calculated from data set 1 using the herd's identification number as the key for merging both databases. The herds not recorded at the DHIA, hence herds without prevalence estimate, were discarded from data set 2 .

\section{Statistical Treatment of Data Set 1}

Process control statistics. The statistics of the capability index were derived from literature (Mitra, 1993; Wadsworth, 1998) and adapted to the purpose of the work. The upper limit of the process specification 
criteria was 400,000 cells $/ \mathrm{mL}$. This limit was taken from EU legislation.

The Cpk was calculated as:

$$
\mathrm{Cpk}=(400,000 \text { cells } / \mathrm{mL}-\mathrm{AAVG}) /\left(3 \mathrm{R}^{\prime} /\left(\mathrm{d}_{2}\right)\right) .
$$

The value of $d_{2}$ is tabulated. It is a function of the number of samples in each month, in our case $n=4$. The tabulated value for $\mathrm{n}=4$ is $\mathrm{d}_{2}=2.059$. The standard deviation of the process can be estimated from $R^{\prime} / d_{2}$.

The annual average of BMSCC (AAVG) is calculated with the monthly averages of BMSCC (AVG) as follows:

$$
\mathrm{AAVG}=\left(\mathrm{AVG}_{1}+\mathrm{AVG}_{2}+\mathrm{AVG}_{3}+\ldots+\mathrm{AVG}_{13}\right) / 13
$$

The AVG is the monthly average and was calculated using 4 bulk milk SCC results $\left(\mathrm{SCC}_{\mathrm{i}}\right)$ randomly taken from the database of the laboratory as:

$$
\mathrm{AVG}=\left(\mathrm{SCC}_{1}+\mathrm{SCC}_{2}+\mathrm{SCC}_{3}+\mathrm{SCC}_{4}\right) / 4
$$

The annual average of the monthly range of the $\operatorname{BMSCC}\left(\mathbf{R}^{\prime}\right)$ is the average of the monthly range of the BMSCC ( $\left.\mathbf{R}_{\mathbf{i}}\right)$ and was calculated as follows:

$$
\mathrm{R}^{\prime}=\left(\mathrm{R}_{1}+\mathrm{R}_{2}+\mathrm{R}_{3}+\ldots+\mathrm{R}_{13}\right) / 13
$$

The monthly range $R_{i}$ is the difference between the highest BMSCC $\left(\mathrm{SCC}_{\max }\right)$ and the lowest $\left(\mathrm{SCC}_{\min }\right)$ of each month and was calculated as:

$$
\mathrm{R}_{\mathrm{i}}=\left(\mathrm{SCC}_{\max }-\mathrm{SCC}_{\min }\right) .
$$

These statistics were performed using the data set 1 .

Further statistical treatment of the data. Three classes of the Cpk, 4 classes of the annual average, and 4 classes of average range were defined to perform a nonparametric analysis of the data. For the capability index the defined classes were: "Cpk class 1" with Cpk $<0$; and "Cpk class 2" with $0 \leq \mathrm{Cpk}<1$; "Cpk class 3 " with $\mathrm{Cpk} \geq 1$. For the annual average the classes were "AAVG class 1" with AAVG < 200,000 BMSCC/mL; "AAVG class 2" with $200,000 \leq \mathrm{AAVG}<400,000$; "AAVG class 3" with 400,000 $\leq$ AAVG < 500,000; and "AAVG class 4" with AAVG $4 \geq 500,000$. For the average range, the classes defined were as: " $R$ ' class 1 " with $R^{\prime}<$ 150,000 BMSCC; " $R$ ' class 2" with $150,000 \leq R^{\prime}<$ 200,000; " $R$ ' class 3 " with $200,000 \leq R^{\prime}<300,000$; " $R^{\prime}$ class 4" with $R^{\prime} \geq 300,000$. The significance of differences between the counts was evaluated with the Kruskal-Wallis test or with the ANOVA and Scheffe's test as appropriate.

\section{Statistical Treatment of Data Set 2}

Data set 2 comprised 264 herds, each one with an estimated annual herd prevalence of subclinical mastitis and a Cpk score. The annual herd prevalence of subclinical mastitis (SMP) was calculated as a proportion, using the number of individual SCC $\geq 200,000$ divided by the total number of individual SCC results from the 13 consecutive months of each herd. Several authors use this threshold for subclinical mastitis detection in composite milk samples of all quarters of the cow (Radostits, 1994; Schukken et al., 1996).

To establish the relationship between the Cpk of each herd and its observed SMP, linear, exponential, logistic, and polynomial models were investigated. The best correlation was found for the logistic regression model used. The validation of the logistic regression model was carried out through the following steps: first the herds in data set 2 were split into 2 groups made up of randomly selected herds (one with 176 farms and the other with the remaining 88). The group with 176 farms was used to build the model, and the other one was used for the model's fitting validation test. In the second step, the initialization parameters of the logistic model were calculated with the 176 herds data, using the least square method in the SOLVER algorithm for Excel. In the third step we have estimated the annual subclinical mastitis prevalence (SMPe) of the second group of herds ( 88 herds) using their Cpk and the logistic model calculated in the previous step. Finally (step 4), predicted and observed SMP were compared, in terms of $\mathrm{R}^{2}$ and the mean squared error of prediction.

\section{RESULTS}

\section{Comparison Between the Annual Average and the Cpk Scores}

The comparison between the results of the AAVG of BMSCS and the Cpk of the 414 herds is presented in Figure 1 and in Table 1. Figure 1 shows that the distribution of the sample is different when the BMSCC annual average or the Cpk describes the herd's annual BMSCC patterns. A group of $250(60.4 \%)$ herds in the sample had an annual average under 400,000 BMSCC but only $84(20.2 \%)$ of these had a Cpk $\geq 1$, while the remaining 168 herds in the group had a "class 2" Cpk (i.e., $0 \leq \mathrm{Cpk}<1$ ). One hundred and sixty four herds in the sample had AAVG higher than 400,000 cells $/ \mathrm{mL}$. Of these, 162 had a Cpk less than zero and 2 had a Cpk equal to zero. In our sample, 3 herds showed a Cpk equal to zero. Of these, 2 allocated in Cpk class 2 belonged to AAVG class 3 (with annual average values of 400,720 and 400,100). The third herd also found in the class 2 of Cpk had an annual average of 398,850 
A

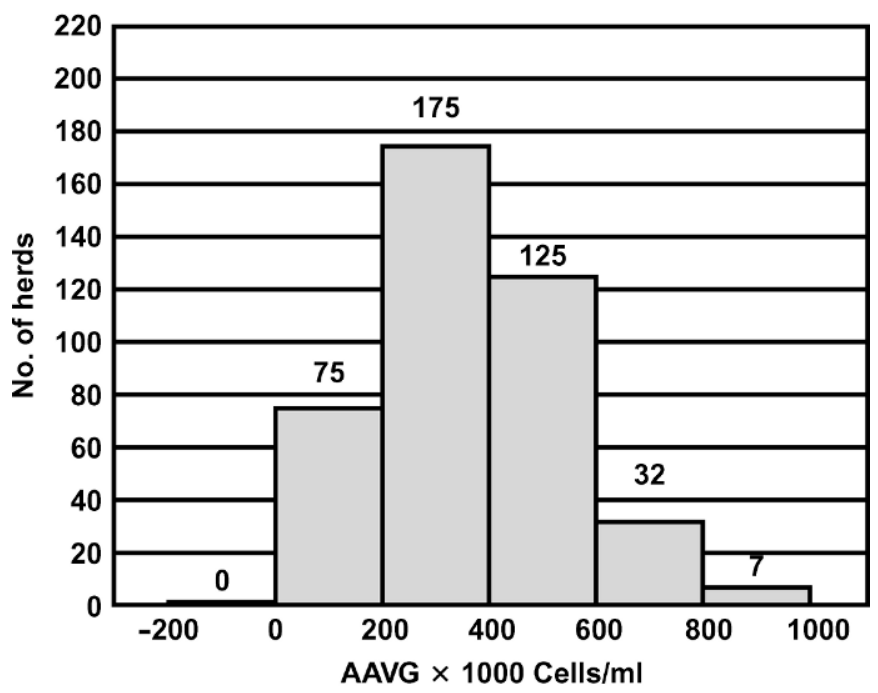

B

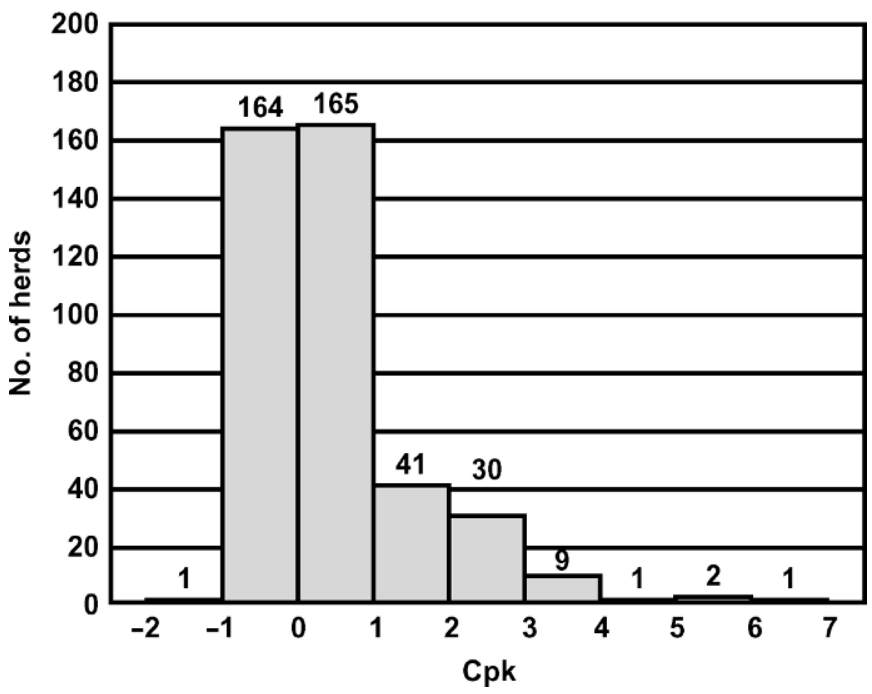

Figure 1. Histogram of the farms in each class of the annual average of the bulk milk SCC (AAVG) (a) and of the capability index (Cpk) (b) of the 414 sampled farms.

BMSCC and was placed in AAVG class 2. The average range values $\left(R^{\prime}\right)$ for these 3 herds were of 273,310 , 324,460 , and $242,460 \mathrm{SCC} / \mathrm{mL}$, respectively.
Table 1 shows that the mean and the median of the AAVG of the 414 herds in the sample is under the EU limit of 400,000 cells $/ \mathrm{mL}$, while the mean and the average of the Cpk are less than one.

In Table 2, the 414 herds are classified in one of the 3 Cpk classes and grouped under combinations of their AAVG and $R^{\prime}$ classes. The overall differences of the counts of farms in Table 2 tested with the KruskalWallis test were significant $(P<0.001)$. Table 2 shows that of the $84.5 \%$ of the 84 herds classified in the best Cpk class had averages under 200,000. The great majority of these 71 herds had range averages under 150,000 SCC and only one had an average range between 150,000 and 200,000 SCC. It was possible, however, to find 13 herds with Cpk in class 3 and annual averages above 200,000 (AAVG class 2), but they had narrow ranges always under 150,000 SCC ( $R^{\prime}$ class 1$)$. Further examining these 13 herds showed that they had annual averages less than 250,000 SCC.

The 168 herds presented in Table 2 with the Cpk between zero and one (class 2) are never found in classes with AAVG under 200,000 SCC and average ranges below 150,000 . Only 4 herds had an average of less than 200,000 SCC, but they have a range above 150,000 SCC. The great majority $92.2 \%$ (155) of the farms with a Cpk class 2 had their annual averages between 200,000 and 400,000 SCC and the average range classes between 150,000 and 300,000. Only 7 herds presented range classes above $300,000 \mathrm{SCC}$.

The 162 herds with values of Cpk below 0 in Table 2 belonged to class 1 of Cpk. Herds with annual averages of less than 400,000 SCC are, of course, not found in this class. The average ranges most frequently found for these herds (90.7\%) are those above 200,000 SCC, although one herd with an average range of less than 150,000 SCC can be found as well as 5 with ranges going from 150,000 to 200,000 SCC.

Table 3 shows the average of the Cpk by the different combinations of annual average classes (in columns) and average range classes (rows). There are some empty cells in this table when there were no farms represented within the combination of the 2 classes. As the annual average class increases, the average $\mathrm{Cpk}$ decreases, and within each average class the Cpk worsens as the average range increases. The overall differences in the aver-

Table 1. Descriptive statistics of the annual average of BMSCC (AAVG), the annual average of the monthly range of BMSCC $\left(\mathrm{R}^{\prime}\right)$ and the capability index (Cpk) from the 414 herds in the sample.

\begin{tabular}{|c|c|c|c|c|c|c|c|c|c|}
\hline & $\begin{array}{l}\text { No. of } \\
\text { herds }\end{array}$ & Mean & Median & Min & Max & $\begin{array}{l}\text { Lower } \\
\text { quartile }\end{array}$ & $\begin{array}{l}\text { Upper } \\
\text { quartile }\end{array}$ & $\begin{array}{l}\text { Quartile } \\
\text { range }\end{array}$ & SD \\
\hline AAI & 414 & 367.36 & 333.66 & 74.19 & 992.13 & 233.31 & 500.74 & 267.43 & 175.12 \\
\hline $\mathrm{R}^{\prime}$ & 414 & 241.04 & 204.31 & 37.62 & 769.15 & 134.54 & 299.62 & 165.08 & 148.29 \\
\hline Cpk & 414 & 0.51 & 0.21 & -1.01 & 6.59 & -0.20 & 0.87 & 1.07 & 1.06 \\
\hline
\end{tabular}


Table 2. Count the capability index (Cpk) of the 414 dairy herds distributed by classes of the annual average of BMSCC (class AAVG) and of the annual average of the monthly range of BMSCC (class $\mathrm{R}^{\prime}$ ).

\begin{tabular}{|c|c|c|c|c|c|c|c|c|c|c|c|c|c|c|}
\hline \multirow{3}{*}{$\begin{array}{l}\text { Cpk } \\
\text { Class }\end{array}$} & \multirow{2}{*}{\multicolumn{2}{|c|}{$\frac{\text { AAVG Class } 1}{\mathrm{R}^{\prime} \text { Class }}$}} & \multicolumn{4}{|c|}{ AAVG Class 2} & \multicolumn{3}{|c|}{ AAVG Class 3} & \multicolumn{4}{|c|}{ AAVG Class 4} & \multirow{3}{*}{$\begin{array}{l}\text { Total } \\
\text { (rows }\end{array}$} \\
\hline & & & \multicolumn{4}{|c|}{$\mathrm{R}^{\prime}$ Class } & \multicolumn{3}{|c|}{$\mathrm{R}^{\prime}$ Class } & \multicolumn{4}{|c|}{$\mathrm{R}^{\prime}$ Class } & \\
\hline & 1 & 2 & 1 & 2 & 3 & 4 & 2 & 3 & 4 & 1 & 2 & 3 & 4 & \\
\hline 1 & 0 & 0 & 0 & 0 & 0 & 0 & 9 & 31 & 18 & 1 & 5 & 21 & 77 & 162 \\
\hline 2 & 0 & 4 & 43 & 56 & 56 & 7 & 0 & 1 & 1 & 0 & 0 & 0 & 0 & 168 \\
\hline 3 & 70 & 1 & 13 & 0 & 0 & 0 & 0 & 0 & 0 & 0 & 0 & 0 & 0 & 84 \\
\hline Total (columns) & 70 & 5 & 56 & 56 & 56 & 7 & 9 & 32 & 19 & 1 & 5 & 21 & 77 & 414 \\
\hline
\end{tabular}

age of Cpk values either within the class AAVG or of the class $\mathrm{R}^{\prime}$ were significant at $P<0.05$ using the ANOVA test.

\section{Model to Predict Herd Subclinical Mastitis Prevalence}

As said before, the logistic regression model showed the best fit with our data. The model can be written as follows: $\mathrm{SMPe}=0.4475 e^{(-0.5286 \times \mathrm{Cpk})}$. The annual subclinical mastitis predicted prevalence of the 88 herds (SMPe) as well as the SMPe of all the 264 herds was estimated using their Cpk with the model. Figure 2 shows the plot of the Cpk of the 264 herds against the respective observed SMP and also depicts the curve of SMPe obtained with the logistic model.

The linear regression model resulting from plotting the SMP against SMPe of the 88 herd group (Figure $3 \mathrm{~A})$ is $\mathrm{SMPe}=0.02+0.94 \times \mathrm{SMP}$. The model showed a correlation coefficient of $0.87\left(\mathrm{R}^{2}=0.75\right)$. Another model resulting from the 264 herds ( $3 \mathrm{~b})$ is $\mathrm{SMPe}=0.06$ $+0.81 \times \mathrm{SMP}$ with a correlation coefficient of $0.85\left(\mathrm{R}^{2}=\right.$ $0.73)$. Both models have a slope near one and significantly different from zero $(P<0.05)$, thus showing that they are indistinguishable from each other from a statistical point of view, as expected from the observations in Figure 3. The typical value of mean squared error of prediction was 0.088 , indicating a mean error of less than $10 \%$, which is acceptable given that the data used gathered under field conditions.

\section{DISCUSSION}

\section{Cpk Describes the Udder Health at the Farm Better than the Average}

Observing the distribution in Figure 1a we can see in our sample a group of 250 herds with annual averages less than 400,000 BMSCC. These 250 herds are also represented in Figure 1b, but only part of them showed a Cpk $\geq 1(\mathrm{n}=84)$. With the Cpk equation it becomes clear that the 84 herds with $\mathrm{Cpk} \geq 1$ (classified in class Cpk 3) never delivered milk out of the specification criteria (i.e., above the legal limit of SCC) during the year under evaluation with $99.75 \%$ confidence. The other 166 farms from the group of 250 (Figure 1a), are found in the group with Cpk less than or equal to one and greater than zero (Figure 1b). Although these farms had their annual average under 400,000 SCC, they delivered part of their BMT above this value throughout the year. This explains why the mean and median AAVG of all the herds is 367,000 and 333,700 , respectively, while the mean and median capability index is 0.5 and 0.2 , respectively (Table 1 ). There are 2 farms with $\mathrm{Cpk}=0$ but with AAVG only slightly higher than 400,000 as discussed above. These herds had average annual ranges in their monthly BMSCC higher than 250,000 cells. In fact, their records show that, during the year, they had delivered some BMT with until $650,000 \mathrm{SCC} / \mathrm{mL}$ in the milk. It is therefore clear that, in terms of milk quality, the supply of the 166 herds with annual averages under 400,000 SCC but at the

Table 3. Mean of the capability index of the herds included in all the possible combination of classes of the annual average of BMSCC (Class AAVG) and of the annual average of the monthly range of BMSCC (Class $\left.\mathrm{R}^{\prime}\right)$.

\begin{tabular}{lllllr}
\hline Classes & $\begin{array}{l}\text { AAVG } \\
\text { Class 1 }\end{array}$ & $\begin{array}{l}\text { AAVG } \\
\text { Class 2 }\end{array}$ & $\begin{array}{l}\text { AAVG } \\
\text { Class 3 }\end{array}$ & $\begin{array}{l}\text { AAVG } \\
\text { Class 4 }\end{array}$ & $\begin{array}{r}\text { Total } \\
\text { (rows) }\end{array}$ \\
\hline $\mathrm{R}^{\prime}$ Class 1 & 2.38 & 0.88 & $-{ }^{1}$ & -0.61 & 1.71 \\
$\mathrm{R}^{\prime}$ Class 2 & 0.92 & 0.46 & -0.23 & -0.64 & 0.34 \\
$\mathrm{R}^{\prime}$ Class 3 & -1 & 0.27 & -0.13 & -0.44 & 0.02 \\
$\mathrm{R}^{\prime}$ Class 4 & -1 & 0.10 & -0.11 & -0.38 & -0.29 \\
Columns' average & 2.29 & 0.52 & -0.14 & -0.40 & 0.51 \\
\hline
\end{tabular}

${ }^{1}$ There were no herds in this particular combination of classes. 


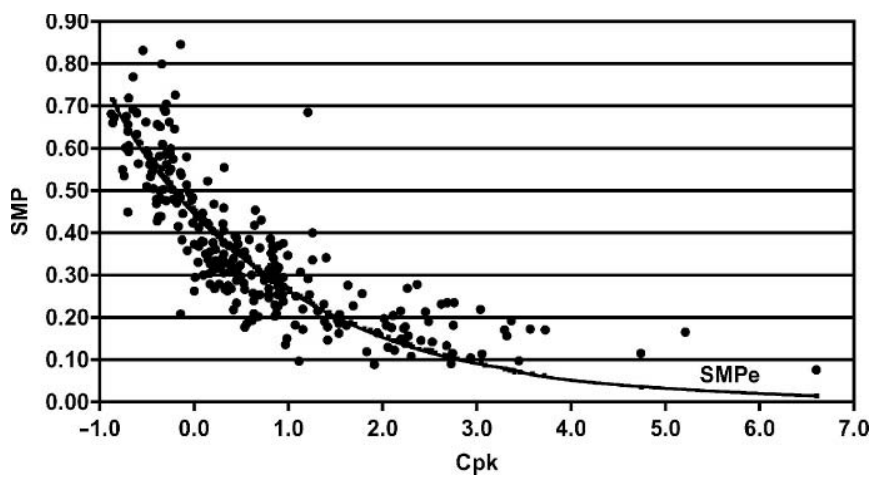

Figure 2. Scatter plot diagram of the annual prevalence of subclinical mastitis (SMP) as function of the capability index (Cpk). Each farm is represented by $(\bullet)$ and the black line represents the estimated annual prevalence of subclinical mastitis (SMPe).

same time with Cpk under one are not as consistent as those herds with a Cpk greater or equal to one. From the perspective of compliance with the legal specifications, the last were consistent in their supply, whereas the former were not. This is why the use of Cpk is a better option than the BMSCC average in farm vendor rating models in the quality systems of the dairy industry. Implications of this issue will be discussed further in the text.

Another issue is how the AAVG and the average range $\left(R^{\prime}\right)$ interact to influence the Cpk. The results presented in Tables 2 and 3 show how this interaction works. It can be seen that the herds with AAVG less than 200,000 and $R^{\prime}$ less than 150,000 have the highest Cpk mean (Table 3). Additionally, the herds within AAVG class 2 (average values between 200,000 and 400,000 SCC) only have Cpk $\geq 1$ if they have a narrow variation in their BMSCC (class $R^{\prime} 1$ ). An interesting observation (Table 2) is that in AAVG classes 2, 3, and 4 there are farms with the whole range of $R^{\prime}$ classes, creating empirical evidence that the AAVG contributes more to the Cpk outcome of a farm than the $\mathrm{R}^{\prime}$. But Table 3 also shows that for each AAVG class as the range worsens when the mean Cpk decreases. The differences in the Cpk mean in Table 3 are statistically significant $(P<0.05)$. Even though the 3 classes of $\mathrm{Cpk}$ have groups of farms with significantly different AAVG and $R^{\prime}$, among all the possible combinations of AAVG and $R^{\prime}$ classes some are, of course, impossible to find, e.g., AAVG class 1 with $\mathrm{R}^{\prime}$ of class 3 or 4 (Tables 2 and 3 ).

An important advantage of the use of the Cpk over the annual average of BMSCC is that it enables the creation of 3 mathematically and statistically significant different groups of farms: the farms with Cpk below zero, between zero and one, and above one. According to the results from the ANOVA test in Tables
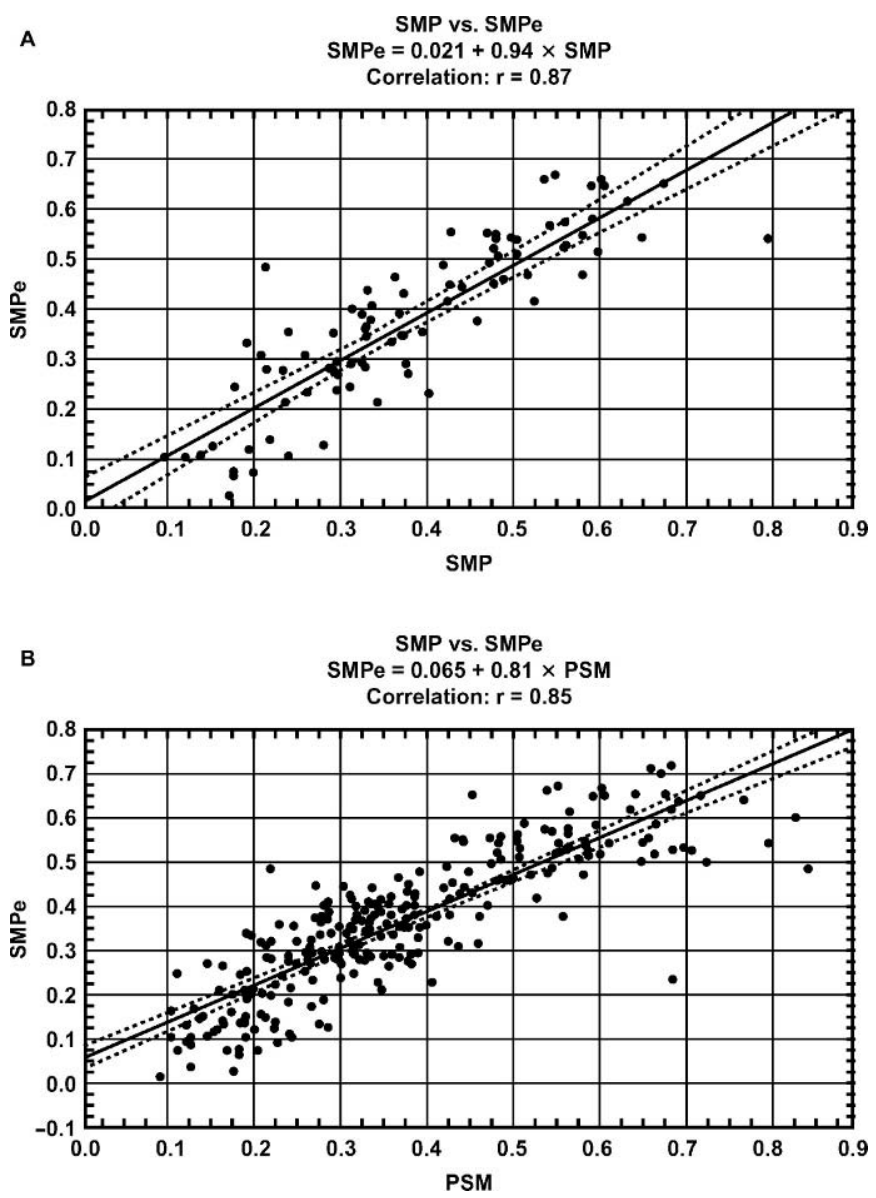

Figure 3. Diagram of subclinical mastitis prevalence (SMP) plotted against the expected subclinical mastitis prevalence (SMPe) as predicted by the logistic regression model (top) with the 88 herds group and (bottom) with the 264 herds group.

2 and 3 , these 3 groups are statistically different and they represent different levels of milk quality. Remember that the Cpk was calculated for each farm using its AAVG of the monthly BMSCC averages and the annual average range $\left(R^{\prime}\right)$ based on the monthly ranges of the BMSCC and also took into account the legal EU limit for BMSCC, 400,000 cells/mL. Using the Cpk equation, it is therefore possible to take into consideration, simultaneously, the legal limit of the SCC and both statistical parameters that describe its behavior in the BMT: central tendency (AAVG) and dispersion $\left(\mathrm{R}^{\prime}\right)$. That is why it can be stated that the farms in each group have statistically different consistency in their milk SCC and comply differently from a legal perspective.

The results discussed above provide evidence that the use of SCC averages to describe, monitor, or evaluate the somatic cell content in a farm's output of milk could be replaced with advantage by the use of the Cpk. The Cpk is a robust indicator of the herd milk quality 
performance, since it is calculated using a representative sampling procedure intended not only to represent $1 \mathrm{yr}$ of production of the farm, batch after batch of BMT, but also to predict the expected BMT behavior of the following year.

\section{Validation of the Cpk to Predict Subclinical Mastitis Prevalence}

The majority of the somatic cells present in the bulk milk tank are shed in the milk by infected cow quarters. To enable the farmer or the veterinarian to keep the BMSCC below the legal limit instead of reacting to an existing situation requires the possibility of acting on the producing cows of the herd in a quantitative way. It was therefore necessary to relate the prevalence of subclinical mastitis with not only the average of the BMSCC but also with the variation associated to it. Since the Cpk takes account of both the average and the variation of the somatic cell level in the BMT, we looked for a model to relate the Cpk and the herd subclinical mastitis prevalence.

The logistic regression model presented above has shown an excellent ability to relate the Cpk of dairy herds with their SMP (Figure 2). It was then decided to validate the model by testing its ability to predict the herd subclinical mastitis prevalence from the respective Cpk score and by comparing the predicted with the observed annual SMP. Two comparisons were made, one with data from 88 herds not previously used in the calculation of the model and the other with the data from all herds. The correlations obtained, 0.87 and 0.85 , respectively, showed that the calculated logistic model has good ability to predict the herd's annual mastitis prevalence.

Figure 3 shows some discrepancy in the herds located at the extreme values of the model and shows a good fit for SMP between 0.2 and 0.5. These herds can also be seen as outliers in Figure 2. In the case of the extreme values related with high and very low $\mathrm{Cpk}$, the deviation of the SMP from what could be expected is probably related to the fact that farmers involved discard the milk of many subclinically and clinically affected quarters. The same situation occurs at the highest SMP, where some Cpk scores are better than the expected. These procedures at some farms affect the Cpk estimation because the milk sample taken from the BMT does not reflect the SCC of all the cows in the herd. Therefore, some farms perform differently than what would have been expected considering the udder health status of the herd. In a way, these farmers are already implementing measures to reduce the number of their farm violations regarding the SCC in the BMT.

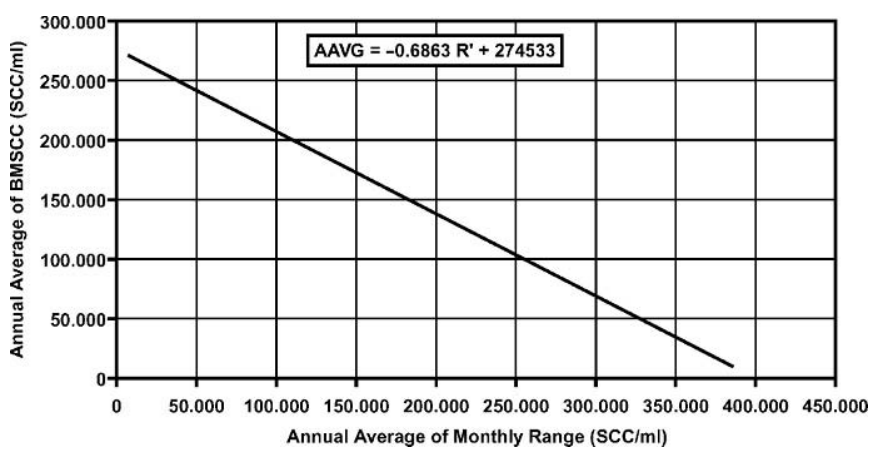

Figure 4. Straight line drawn throughout the plot of points for which the combination of the annual average of the bulk milk tank somatic cell count (AAVG) and annual average range $\left(R^{\prime}\right)$ give capability index values of one. The equation for this line is presented at the top of the figure.

The 2 linear models used to evaluate the precision of the logistic regression model to estimate the annual subclinical mastitis prevalence (see Figure 3) show excellent correlation. The fact that the correlation between the observed and the estimated prevalence in the subgroup of 88 herds (not used to build the logistic model) was statistically significant provides strong evidence of the goodness of our model.

\section{Use of the Cpk to Support the Herd Udder Health Management}

Specification of an objective of SCC to the BMT. This subject often poses problems because it is not easy to calculate the associated variability. A target of between 200,000 and 250,000 is recommended to ensure that the herd remains under the penalty levels of $400,000 \mathrm{SCC} / \mathrm{mL}$ (Schuken et al, 1996). This is a very general recommendation that ignores knowledge of each individual herd. The Cpk can be very useful in helping to solve this problem at the level of the individual herd. This is possible because although the distribution of the individual bulk milk SCC results is generally not normal, the BMT AAVG, calculated as above, is expected to follow the central limit theorem. According to this theorem (Dudewicz, 1998), when a population is sampled several times, the population average of the averages, calculated with the averages from each sample, follows a normal distribution even if the parameter is not normally distributed in the source population. Because the annual average of SCC (AAVG) is an average of the averages of $13 \mathrm{mo}$, it is expected to follow the normal distribution. Consequently it allows a statistical inference about the probability of occurrence of any values of SCC from the particular bulk milk tank the sample was taken from. 
Each herd has its own Cpk as a result of a particular combination of AAVG and $R^{\prime}$ of its process. We calculated some of the possible combinations of AAVG and $R^{\prime}$ that give Cpk equal to one and plotted them in Figure 4. It is possible to draw a straight line under which area the combination of values that are compatible with $\mathrm{Cpk}$ greater than one lie. Its equation is AAVG = $274,533+\left(-0.6863 \times \mathrm{R}^{\prime}\right)$. This equation is useful to calculate the objective of BMSCC for each herd, taking the specific farm variation mathematically into account.

Using the AAVG and the $\mathrm{R}^{\prime}$, it is possible to calculate the upper control limit for the annual average (UCL AAVG) of the process using the following formulas $\mathrm{UCL}=\mathrm{AAVG}+0.73 \times \mathrm{R}^{\prime}$ and the upper control limit for the range (UCL $R^{\prime}$ ) $R C L R=R^{\prime} \times 2.28$ (Mitra, 1993). As an example, a farm with an AAVG of 320,000 cells/ $\mathrm{mL}$ and a $\mathrm{R}^{\prime}$ of 70,000 has a Cpk of 0.80 a UCL AAVG of 371,100 and a UCL $R^{\prime}$ of 159,000 cells $/ \mathrm{mL}$. These are useful reference values for management because the UCL AAVG shows what will be the highest value of the monthly average (AVG) of the BMSCC 9975 out of 10,000 deliveries and the same for the $\mathrm{R}^{\prime}$.

Objective setting for SMP. Herd health managers need to set objectives in udder health prevention and control plans (Schukken et al., 1996). To be accomplished, they have to rely on the control of mastitis prevalence. According to our results, it is possible to predict the herds' annual SMP using the respective Cpk with a good level of confidence. The opposite is also true, i.e., it is possible to assign goals of SMP to the herd in order to achieve the objectives set for SCC in the bulk milk tank. If the objectives in the BMSCC are specified according to the European Union standard limit of 400,000 SCC/mL, a goal of SMP derived from a Cpk equal to or greater than one will be enough to comply consistently. Therefore, goals on SMP can be assigned to herds using the logistic regression model presented in this paper. It is possible to propose a critical limit of 0.26 to the annual SMP at the dairy herd. According to our results, a SMP below 0.26 would be sufficient to allow the compliance of the herd with the legal limit allowed for BMSCC by preventing the excess of contamination of the milk with somatic cells. This is an important target for managers responsible for udder health control and prevention programs such as the ones proposed by Radostits et al. (1994) and Schukken et al. (1996).

\section{Use of Cpk by Other Actors Involved in the Milk Chain}

As already noted, the Cpk can be used by either the industry or by the official inspection services to evaluate and to follow the farm as a food chain supplier in terms of both the quality and consistency of its production.

The industry. In many countries, the industry already pays for milk quality using the SCC, through BMSCC averages. If the Cpk were used instead, discrimination between consistent and irregular farms would be allowed and would be reflected in the bonuses or payment schemes. The adoption of Cpk would provide an important orientation to the farm managers stressing the need for the adoption of effective prevention programs. The underlying rationale is that farms consistent and compliant with the standard show a Cpk equal to or greater than one and are statistically different from some herds presenting acceptable annual averages but with monthly unacceptable fluctuations (see Figure $1 \mathrm{a}$ and $\mathrm{b}$ and Table 3 ). The former need to have effective mastitis control and well managed and monitored prevention programs (of course, more investment and expert knowledge is necessary to maintain the system), whereas the latter are mainly reacting to the occurrence of mastitis. Another issue of increasing importance is that many dairy plants are adopting quality systems and hazard analysis and critical control point (HACCP) plans combined with good hygiene practices. The raw material coming into the plant has to comply with legal standards, and vendor rating schemes are commonly adopted to evaluate the quality of the supplier. Shifting the vendor rating systems for SCC from BMSCC average to the Cpk will provide an increased confidence that, for herds with a annual Cpk equal to or greater than one, the farm supply will permanently comply with the regulations.

The adoption of the Cpk by legal authorities in charge of the verification of dairy farm compliance with the regulations and standards will enable them to easily detect the farms that are not complying among those with good averages. This will save a lot of hard labor and time in expensive sampling plans to detect noncompliant farms. It also will provide an overall picture of dairy farm's regional or national herd udder health status.

The Cpk could also be used in international disputes. Because the Cpk allows comparisons between several different milk supply systems, from different countries with different herd health managements, the Cpk can be used to apply the equivalence principle for udder health issues at the farm.

A final advantage of the Cpk is that it can be implemented with SCC data, which are already generated under current milk pricing systems worldwide so that no additional costs are to be expected from its use.

\section{Further Investigation}

Further investigation should be carried on the influence and interactions of mastitis pathogens on the Cpk. 
The possibilities of further use of the Cpk to help in critical control point management at the herd level should also be highlighted, because there seems to be potential for this SPC tool to be effective with the quantitative aspects of the HACCP system. In the last few years, the HACCP concept has been proposed as an effective way to enhance food safety along the food chain including the dairy farm (Codex Alimentarius Commission, 2001). Although the preharvest sector has been considered a step during which HACCP systems seemed to be difficult to implement (Cullor, 1997), the Codex Alimentarius Commission (2001) still recommends the pursuit of an HACCP compatible approach, whenever possible, at every step of the food chain.

\section{CONCLUSIONS}

In this work, we have established the capability index, Cpk, as a robust indicator of the milk SCC quality performance. When compared with the traditional BMSCC average, the Cpk showed better accuracy to describe the herd's ability to comply with the legal standard limits imposed on BMSCC. Based on this index, it was possible to separate 3 types of farms according to their compliance: farms that permanently comply had Cpk $\geq 1$, farms that comply intermittently had $0 \geq$ Cpk $<1$, and farms that did not comply at all showed a $\mathrm{Cpk}<0$.

It was shown that the Cpk can be advantageously used as a predictive tool for udder health management programs in dairy farms, replacing the BMSCC average. With the use of $\mathrm{Cpk}$ it is possible to produce objectives to the BMSCC and goals of SMP oriented to comply with the hygiene standards for SCC in ex-farm milk. A set of equations was developed for that purpose. The first is a logistic regression model to estimate the target for annual subclinical mastitis prevalence for the desired Cpk. The second is an equation that allows the calculation of the average of BMSCC using the range of BMSCC, in order to have a permanent BMSCC under the SCC limit.

It was shown that the Cpk is an ideal tool for vendor rating in quality management systems and can be used by either the industry or the official inspection services to evaluate and to verify the farm compliance as a supplier in terms of the safety and consistency of its production. Another use of the Cpk can be in international disputes, because it allows the comparison of several different milk supply systems.

\section{ACKNOWLEDGMENTS}

The authors thank Adriana Esteves for helping in the handling of the databases used in this work. This research was performed in project Leitagro'Q-Praxis XXI P-1303 and funded by Praxis XXI, FEDER, and AGROS and sponsored by Portuguese Ministery of Technology and Science and Agência de Inovação.

\section{REFERENCES}

Barkema, H. W., J. D. Van der Ploeg, Y. H. Schukken, T. J. G. M. Lam, G. Benedictus, and A. Brand 1999. Management style and its association with bulk milk somatic cell count and incidence rate of clinical mastitis. J. Dairy Sci. 82:1655-1663.

Codex Alimentarius Commission. 2001. Basic Texts on Food Hygiene. 2nd ed. Joint FAO/WHO Food Standards Programme. FAO, Rome, Italy.

Cullor, J. S. 1997. HACCP (hazard analysis and critical control points): Is it coming to the dairy? J. Dairy Sci. 80:3449-3452.

Dudewics, E. J. 1998. Basic statistical methods. Section 44.34 in Juran's Quality Handbook. J. M. Juran and A. B. Godfrey. 5th ed. McGraw-Hill, New York, NY.

Eberhart, R. J., L. J. Hutchinson, and S. B. Spencer. 1982. Relationships of bulk tank somatic cell counts to prevalence of intramammary infection and to indices of herd production. J. Food Prot. $45: 1125-1128$.

Fetrow, J., S. Stewart, S. Eicker, R. Farnsworth, and R. Bey. 2000. Mastitis: An economic consideration. Page 3047 in Proc. Natl. Mastitis Council Annu. Mtg. National Mastitis Council, Madison, WI.

Ford. 1987. Pages 48 to 56 in Statistical Process Control: Instruction Guide EU 880 ${ }^{\mathrm{a}}$. Ford Motor Company, Detroit, MI.

International Dairy Federation. 1997. Part 1: Somatic Cell Count. Recommendations for Presentation of Mastitis-Related data. Bull. IDF 321:10-15.

International Dairy Federation. 1994. The Significance of Pathogenic Microorganisms in Raw Milk. G. Han and W. Heeschen, eds. IDF, Brussels, Belgium.

International Dairy Federation. 2000. Mammary gland immunological components. Pages 31-33 in IDF Position Paper on Ruminant Mammary Gland Immunity. A. Zecconi and K. L. Smith. IDF, Brussels, Belgium.

Klei, L., J. Yun, A. Sapru, J. Lynch, D. Barbano, P. Sears, and D. Galton. 1998. Effects of milk somatic cell count on cottage cheese yield and quality. J. Dairy Sci. 81:1205-1213.

Koldeweij, E., U. Emanuelson, and L. Janson. 1999. Relation of milk production loss to milk somatic cell count. Acta Vet. Scand. 40:47-55.

Mitra, A. 1993. Part III-Statistical process control. Pages 293 to 327 in Fundamentals of Quality Control and Improvement. Macmillan Publishing Company, New York, NY.

Radostits, O. M., K. E. Leslie, and J. Fetrow. 1994. Mastitis control in dairy herds. Pages 229-276 in Herd Health: Food Animal Production Medicine. 2nd ed. W. B. Saunders Company, Philadelphia, PA.

Reneau, J. K. 2000. Process control: Timely feedback for milk quality production at the farm. Pages $140-148$ in Proc. Natl. Mastitis Council 39th Annu. Mtg. National Masititis Council, Madison, WI.

Schällibaum, M. 2000. Impact of SCC on the quality of fluid milk and cheese. Pages 38-46 in Proc. Natl. Mastitis Council 40th Annu. Mtg. National Mastitis Council, Madison, WI.

Schalm, O. W., E. J. Carrol, and N. C. Jain. 1971. Number and types of somatic cell count in minormal and mastitic milk. Pages 94127 in Bovine Mastitis. Lea and Febiger, Philadelphia, PA.

Schukken, Y. H., and W. D. J. Kremer. 1996. Monitoring udder health: Objectives, materials and methods. Pages 351-361 in Herd Health and Production Management in Dairy Practice. A. Brand, J. P. T. M. Noordhuizen and Y. H. Schukken, eds. Wageningen Pers Publ., Wageningen, The Netherlands.

Wadsworth, H. M. 1998. Statistical Process Control. Section 45 in Juran's Quality Handbook. J. M. Juran and A. B. Godfrey, eds. 5th ed. McGraw-Hill, New York, NY. 